EPiC Series in Engineering
Volume 3, 2018, Pages 1822-1831
HIC 2018. 13th International
Conference on Hydroinformatics

\title{
Development and Application of a User- Friendly Decision Support Tool for Optimization of Wastewater Treatment Technologies in India
}

\author{
Seyed M. K. Sadr ${ }^{1}$, Matthew B. Johns ${ }^{1 *}$, Fayyaz A. Memon ${ }^{1}$, Mark \\ Morley ${ }^{1}$, Dragan A. Savić ${ }^{1}$ \\ ${ }^{1}$ Centre for Water Systems, College of Engineering, Mathematics and Physical Sciences, Harrison \\ Building, North Park Road, University of Exeter, Exeter, Devon, EX4 4QF, United Kingdom. \\ s.m.k.sadrdexeter.ac.uk, m.b.johnsdexeter.ac.uk, \\ f.a.memondexeter.ac.uk, m.s.morleydexeter.ac.uk, \\ d.savicexeter.ac.uk
}

\begin{abstract}
The selection of suitable wastewater treatment solutions is a complex problem that requires the careful consideration of many factors. With water at a premium and water consumption increasing, India is facing a challenging time ahead, requiring effective water treatment solutions. The Wastewater Decision Support Optimizer (WiSDOM) presented here is a user-friendly software package designed to aid in the formulation and configuration of wastewater systems in developing countries such as India. WiSDOM employees advanced multi-objective optimization and decision analysis techniques to identify optimal wastewater treatment options. It has been demonstrated that WiSDOM can adapt to a wide array of scenarios, considering a range of contributing factors (technical, environmental, economic and social), enabling stakeholders to make more informed decisions. The tool was applied to three different scenarios to test its functionalities and assess treatment technologies potential for different contexts. Initial results suggest that it is possible to automatically generate feasible distinct treatment strategies for user-defined contexts/constraints.
\end{abstract}

\section{Introduction}

India represents about $1 / 6^{\text {th }}$ of the world population but accounts for $1 / 25^{\text {th }}$ of water resources of the world (Kaur et al., 2012). Due to population growth, the water demand is expected to increase while, per capita average annual water availability has been reducing from $5177 \mathrm{~m}^{3}$ in 1951 to $1588 \mathrm{~m}^{3}$ in 2010 (CWC., 2010). In addition, due to rapid urbanisation and growth in the quality of life, the 
wastewater generation has significantly increased and expected to increase further (Kumar et al., 2016). Therefore, there are two major challenges in India in the coming years: 1) reduced freshwater availability and 2) increased wastewater generation. However, irrigation accounts for about 85 per cent of water usage in India and the majority of this amount could be potentially managed by treated wastewater, therefore, water reuse would be a promising solution to overcome water related challenges in India. The selection of suitable wastewater treatment (WWT) solutions is a complex process (Ren and Liang, 2017), where several factors need to be considered (Arroyo and Molinos-Senante, 2018; Memon et al., 2016); this is especially the case in India where a wide variety of socio-economic and environmental contexts exist. This results in the need to include a range of decision objectives and criteria (e.g. capital, operational and maintenance costs, energy consumption, chemical requirement, land requirement, and reliability) in the process of formulating WWT solutions.

A review of the literature suggests that there are a number of studies which have developed and presented WWT technology selection tools/models (Arroyo and Molinos-Senante, 2018; Kalbar et al., 2013; Karimi et al., 2011; Ren and Liang, 2017; Sadr et al., 2015) (among other studies). Some studies employed multi criteria decision analysis (MCDA) methods to select the most optimal technologies (Anagnostopoulos et al., 2008; Arroyo and Molinos-Senante, 2018; Aydiner et al., 2016; Kalbar et al., 2013); some others used multi objective optimisation (MOO) approaches to synthesise treatment train and identify the best solutions (Chen and Beck, 1997; Hakanen et al., 2011; Joksimovic et al., 2006; Joksimović, 2006; Krovvidy, 1998). A number of studies considered only a few technologies/alternatives in specific contexts (Aydiner et al., 2016; Kalbar et al., 2013; MolinosSenante et al., 2015; Plakas et al., 2016), and some encompassed very limited number of objectives/criteria (Kalbar et al., 2013, 2012). To the authors' best knowledge (to date), there is no user-friendly decision support tool (DST) for identification and selection of wastewater treatment technologies/trains which employs both MCDA and MOO approaches, whilst, including a large number of WWT unit processes and packaged technologies, and considering various technical, environmental, socio-economic decision criteria and objectives. Therefore, this study describes the development and application of a novel user-friendly DST called WaStewater Decision support OptiMiser (WiSDOM), designed to synthesise treatment trains and identify appropriate solutions (i.e. highly optimal WWT configurations) based on user-defined contexts. The tool employs a hybrid approach of decision making using both MCDA and MOO, and facilitates the assessment of treatment technologies with respect to a large number of decision objectives and criteria. WISDOM has been developed as part of the SARASWATI project, funded by the European Commission (FP7) and the Government of India.

\section{Methodology}

\subsection{WiSDOM Tool Description}

WiSDOM is a user-friendly decision support tool that employs Multi-Objective Optimization (MOO) techniques and Multi Criteria Decision Analysis (MCDA) to aid the user generate optimal WWT solutions for a wide range of scenarios in the context of India. WiSDOM was developed using a cross-platform GUI Framework written in $\mathrm{C}++$. The software was designed and implemented in a way so that it can be deployed on a variety of operating systems, desktop and mobile. The tool consists of multiple components each contributing to the functionality of the tool.

\subsubsection{Technology Library}

At the core of the tool is the technology library; a database containing detailed information on over 40 unit processes and 10 packaged WWT systems. Each unit process and treatment package has detailed characterisation data including methods and equations for evaluating metrics such as required capital 
investment, operational costs, energy usage, sludge production, and water contaminant removal performance. The technology library database is heavily utilised in the optimisation engine to identify and evaluate candidate treatment solutions.

\subsubsection{Optimization Engine}

The core goal of the WiSDOM optimisation process is to produce a range of treatment trains that perform well in terms of the user-selected objectives whilst meeting the water quality constraints imposed by the Indian water quality standards for the intended water reuse applications. The optimisation engine utilises a Multi-Objective Genetic Algorithm (MOGA) to generate optimal WWT train solutions. The tool includes two MOGAs; the Non-Dominated Sorting Genetic Algorithm-II (NSGA-II) and the Omni-Optimiser (Omni-GA) giving the user the ability to choose to use either. The two algorithms have demonstrated their ability to handle the quirks of practical optimisation problems well and prove suited to the formulation of WWT trains. The user has full control over the formulation of the problem; from defining which objectives are being considered for optimisation to the hydraulic, water quality, and design constraints. The selected MOGA uses context information provided by the user and unit process data from the technology library database to evolve optimal treatment train solutions based on the users defined treatment train configuration.

The primary optimization algorithm employed to optimise treatment train configurations in WiSDOM is the Fast Elitist Non-dominated Sorting Genetic Algorithm (NSGA-II) (Deb et al., 2002). NSGA-II employs a fast non-dominated sorting process to sort each individual (solution) present in the population into a front based on Pareto non-dominance. A solution is said to be non-dominated when no other solution present in the population provides any improved objective values without degrading other objective values. Following the non-dominated sort, a crowding distance is assigned to all individuals in the population. The crowding distance is an estimation of the density of solutions surrounding a particular point in the population and is used to preserve diversity in resultant populations. Tournament selection is used to select parent solutions by comparing solution rank (the front in which the solution resides) and crowding distance. The parent solutions are then passed to the crossover and mutation operators to produce new candidate solutions. These new solutions are then evaluated and placed into the next new population and the process is repeated until the stopping criteria is reached, in this case, the number of algorithm iterations allowed by the user. During the optimization process each newly generated solution is assessed as to its ability to remove the multiple contaminates in the influent wastewater and meet the other constraints such as land availability and available budget for investment, operation and maintenance. If the treatment train does not meet those constraints, the solution is flagged as infeasible. The MOO algorithm will always prioritise feasible WWT trains over those that violate the given constraints of the problem. The resultant set of solutions (treatment trains) following the completion of the MOGA is displayed in the user interface and in the event that any infeasible treatment trains remain in the population, these are flagged informing the user of their presence. To simplify the selection of a suitable solution, Multi-Criteria Decision Analysis (MCDA) is then performed on the resultant solutions generated by the MOGA. The MCA employs a Compromise Programming method (Muthu Nesa Beula and Eswara Prasad, 2012; Zeleny and Cochrane, 1974) to evaluate and rank the solutions based on criterion weighting provided by the user, resulting in the prioritisation of solutions which reflect the user's preferences.

\subsubsection{Graphical User Interface (GUI)}

The user engages with the tool through a Graphical User Interface which is designed to be easy to use whilst providing the user with extensive control over the design and optimisation process. The user interface consists of several tabs (see Figure 1 and Table 1) which guide the user through the necessary steps to perform an optimisation and evaluate WWT trains for their specific contexts. 


\subsection{Technology potential for different development scenarios}

This set of scenarios investigates the impact of development constraints on the technology potential, and is divided into the following three cases: (a) Technology potential for a large-scale metropolitan area with a population of 500,000 inhabitants and limited land availability, (b) Technology potential for a medium-size settlement, with a population of 8,500 inhabitants, facing water scarcity for irrigation and landscaping, and (c) Technology potential for a small remote area with a population of 200 inhabitants and limited availability of skilled labor.

\begin{tabular}{|c|c|}
\hline Main tabs & Description (features) \\
\hline $\begin{array}{l}\text { (a \& b) Welcome } \\
\& \text { user information }\end{array}$ & $\begin{array}{l}\text { These tabs include a description of the purpose and functionality of the tool. They are also } \\
\text { used to gather information on the user, e.g., name, position and level of expertise. }\end{array}$ \\
\hline $\begin{array}{l}\text { (c) Context } \\
\text { definition }\end{array}$ & $\begin{array}{l}\text { This is where the user provides information on the context of their WWT project; e.g. } \\
\text { Name and location of the project, population to be served, wastewater production, land } \\
\text { and budget restrictions and intended use of the treated water. }\end{array}$ \\
\hline $\begin{array}{l}\text { (d) Raw wastewater } \\
\text { information }\end{array}$ & $\begin{array}{l}\text { This tab requires the user to provide information on the influent wastewater characteristics } \\
\text { e.g. contaminants levels, expected daily (or hourly pattern of) volume of wastewater, etc }\end{array}$ \\
\hline $\begin{array}{l}\text { (e) Objectives \& } \\
\text { criteria selection }\end{array}$ & $\begin{array}{l}\text { This tab provides the user with control over the optimisation engine. The first section of } \\
\text { this page allows the user to choose which objectives (e.g. Capital expenditure (CAPEX), } \\
\text { operational expenditure (OPEX), energy consumption, sludge production, labour and land } \\
\text { requirements) the MOGA will use to optimise the proposed WWT train. In the next } \\
\text { section, the user has control over different GA parameters; e.g. MOGA algorithm types } \\
\text { (NSGA-II or Omni-GA), run length, population size, crossover rate and mutation rate. The } \\
\text { user can also choose MCDA criteria and their weights for the evaluation process. }\end{array}$ \\
\hline $\begin{array}{l}\text { (f) WWT train } \\
\text { configuration }\end{array}$ & $\begin{array}{l}\text { This menu enables the user to select/deselect unit processes and set the desired length of } \\
\text { treatment train. }\end{array}$ \\
\hline $\begin{array}{l}\text { (g) MOGA } \\
\text { solutions }\end{array}$ & $\begin{array}{l}\text { The MOGA Solution tab provides the user with the ability to initialise and run the MOGA } \\
\text { Upon completion, the user is presented with the final population of treatment train } \\
\text { solutions and scatter plots are displayed showing the trade-off between the different } \\
\text { objectives for all final solutions. The user can also generate radar charts from the } \\
\text { population of results, allowing the direct visual comparison between individual solutions } \\
\text { in terms of the chosen objectives and contaminant levels. }\end{array}$ \\
\hline $\begin{array}{l}\text { (h) MCDA } \\
\text { solutions }\end{array}$ & $\begin{array}{l}\text { The MCDA is run on the final population of solutions obtained by the MOGA based on } \\
\text { the evaluation. This tab contains a table of MCDA solution rankings which displays } 50 \text { of } \\
\text { the highest ranked treatment train solutions. Each solution can be selected to view } \\
\text { detailed breakdown, including objective and contaminant removal figures for each } \\
\text { individual unit process within the treatment train. Also, a stacked bar chart is designed to } \\
\text { illustrate the performance of each solution in terms of the evaluation criteria selected. }\end{array}$ \\
\hline
\end{tabular}

Table 1: WiSDOM Tool's main tabs and their main features

\section{Results and Discussion}

The defined set of scenarios assess the technology potential using WiSDOM based on variations in assumptions/parameters; this aims to fully explore the tool's ability to produce optimal WWT configurations for various situations. A cross-section of eight solutions are presented from the generated results. For each scenario, NSGA-II is applied with a population size of 50, a cross-over rate of 0.85 and mutation rate of 0.15 . The optimization is run for 500 generations before the final population 
achieved. The results obtained from the tool and the corresponding discussions (for one scenario set, as an example) are provided below:

(a)

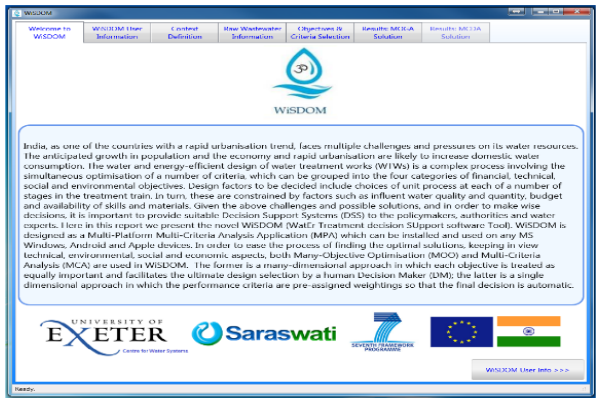

(c)

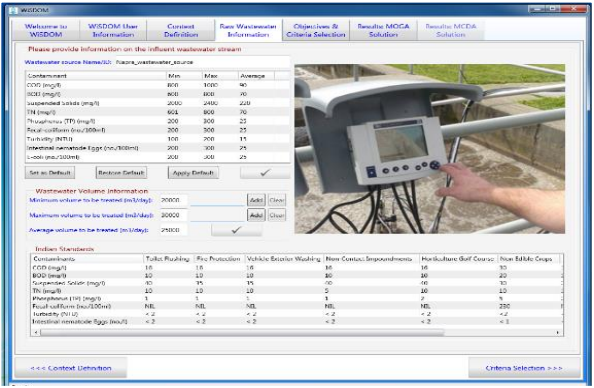

(e)

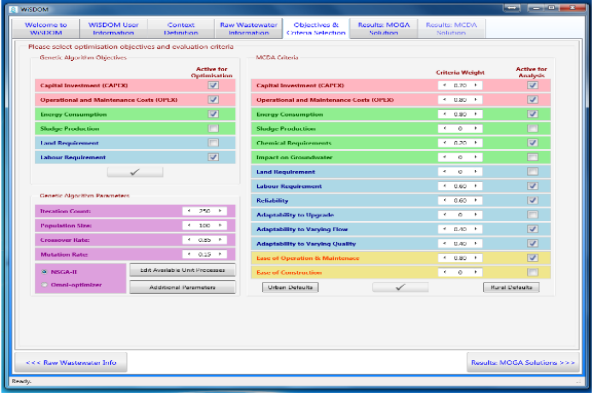

(g)

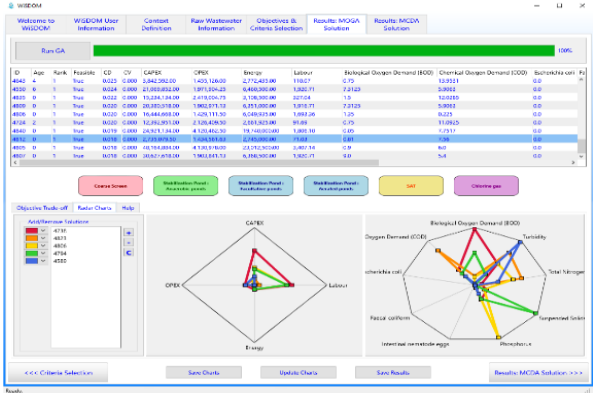

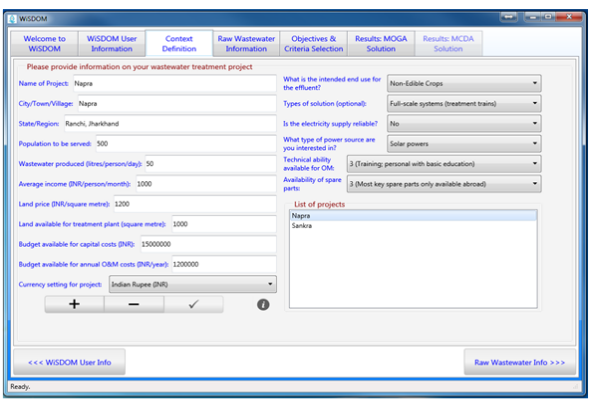

(b)

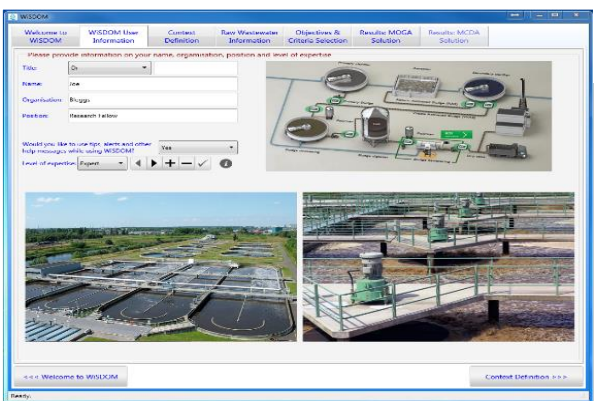

(d)

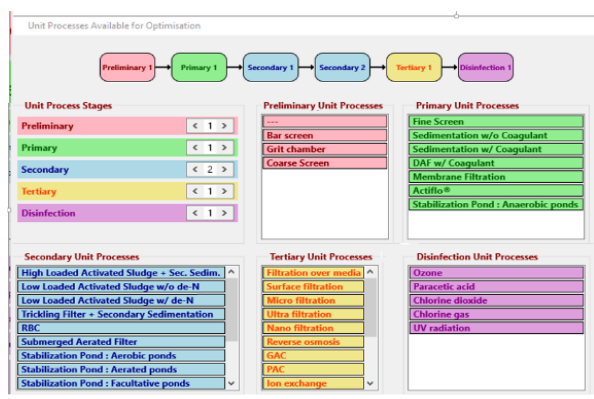

(f)

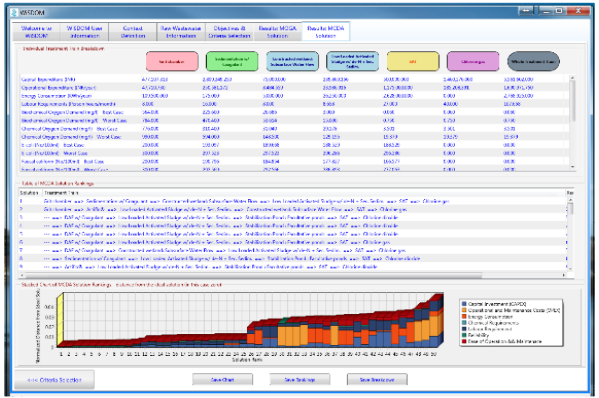

Figure 1: Main tabs/sections in WiSDOM: (a) Welcome to WiSDOM; (b) User Information; (c) Context Definition; (d) Raw Wastewater Information; (e) Objectives \& Criteria Selection; (f) Treatment Train Configuration and Available Unit Processes Dialog Box; (g) Results on MOGA Solutions after optimization completion (Radar charts); (h) Results on MCDA Solutions and details on costs, energy and contaminant level of each unit process (in a treatment train) and each synthesized treatment train (optimal solution) 


\subsection{Technology potential for different development scenarios}

This scenario set, as an example, uses Maharashtra State. Its capital city is Mumbai, and is located in the western region of India. In this state, there are some metropolitan areas such as Mumbai and Pune with urban, semi urban and rural areas. Therefore, different levels of urban development have been considered as scenarios. The three sub scenarios are defined as follows: Scenario (A) is on the technology potential of a metropolitan area with a population of 500,000 inhabitants with very limited land availability. The treated wastewater is aimed to be reused for toilet flushing and fire protection purposes. Scenario (B) describes a medium sized settlement with a population of 8,500 inhabitants with a focus on technology to address water scarcity with horticultural irrigation as the intended water reuse option. Scenario (C) presents a small remote rural area with very limited availability of skilled labour for system operation and maintenance. The intended use of treated wastewater is agricultural irrigation.

The results shown in Figure 2(i), Figure 3(i) and Figure 4(i) (for sub-scenarios A, B and C, respectively) reveal that the optimal composite technologies (treatment trains), generated and selected by the WiSDOM Tool in these sub-scenarios, are acceptable since they are generally performing well with respect to all four (or three of four) selected objectives (e.g. Capital Expenditure (CAPEX), Operational and Maintenance Expenditure (OPEX), Land Requirement, and Labour Requirement).
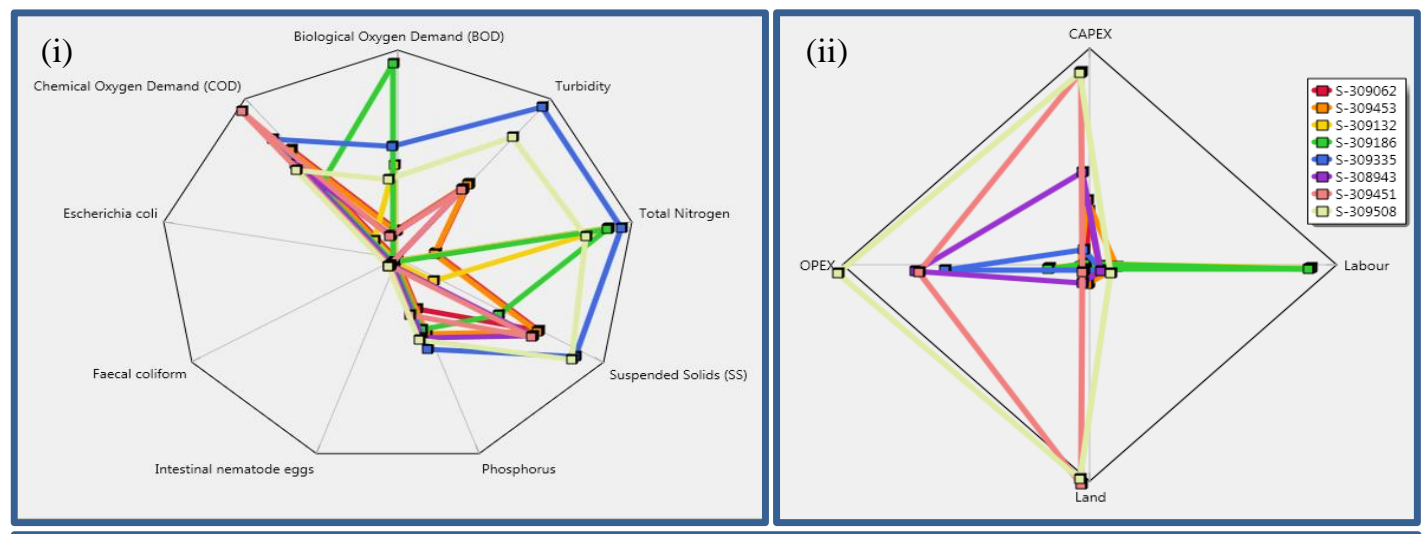

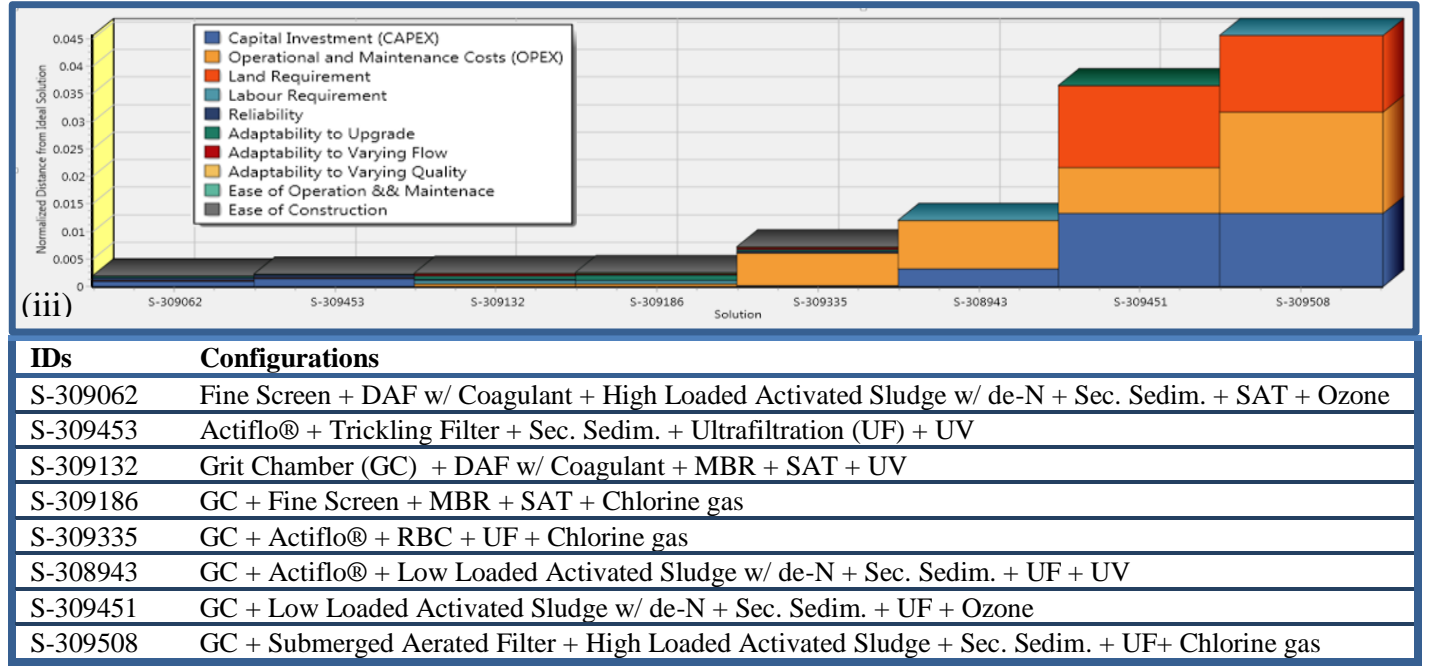

Figure 2: Performance of the optimal WWT trains in this sub-scenario A: (i) contaminant removal star chart; (ii) star chart on the MOO results; and (iii) stacked bar chart on the MCDA results. 

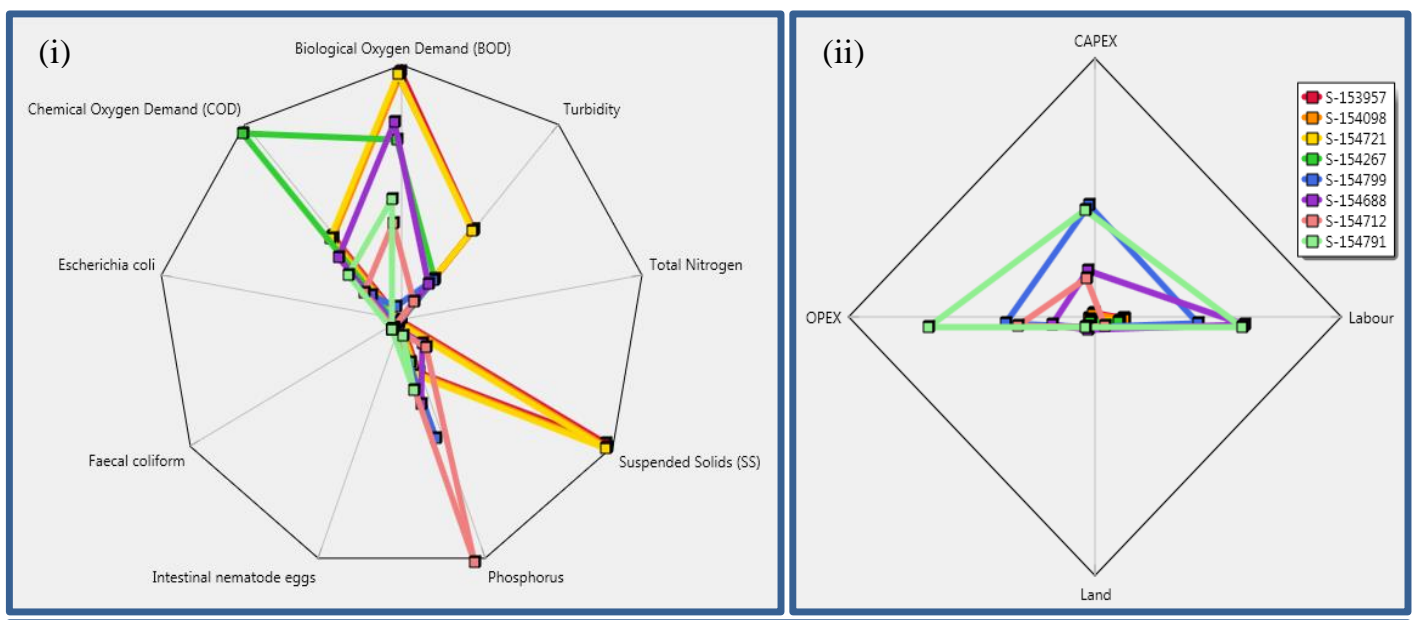

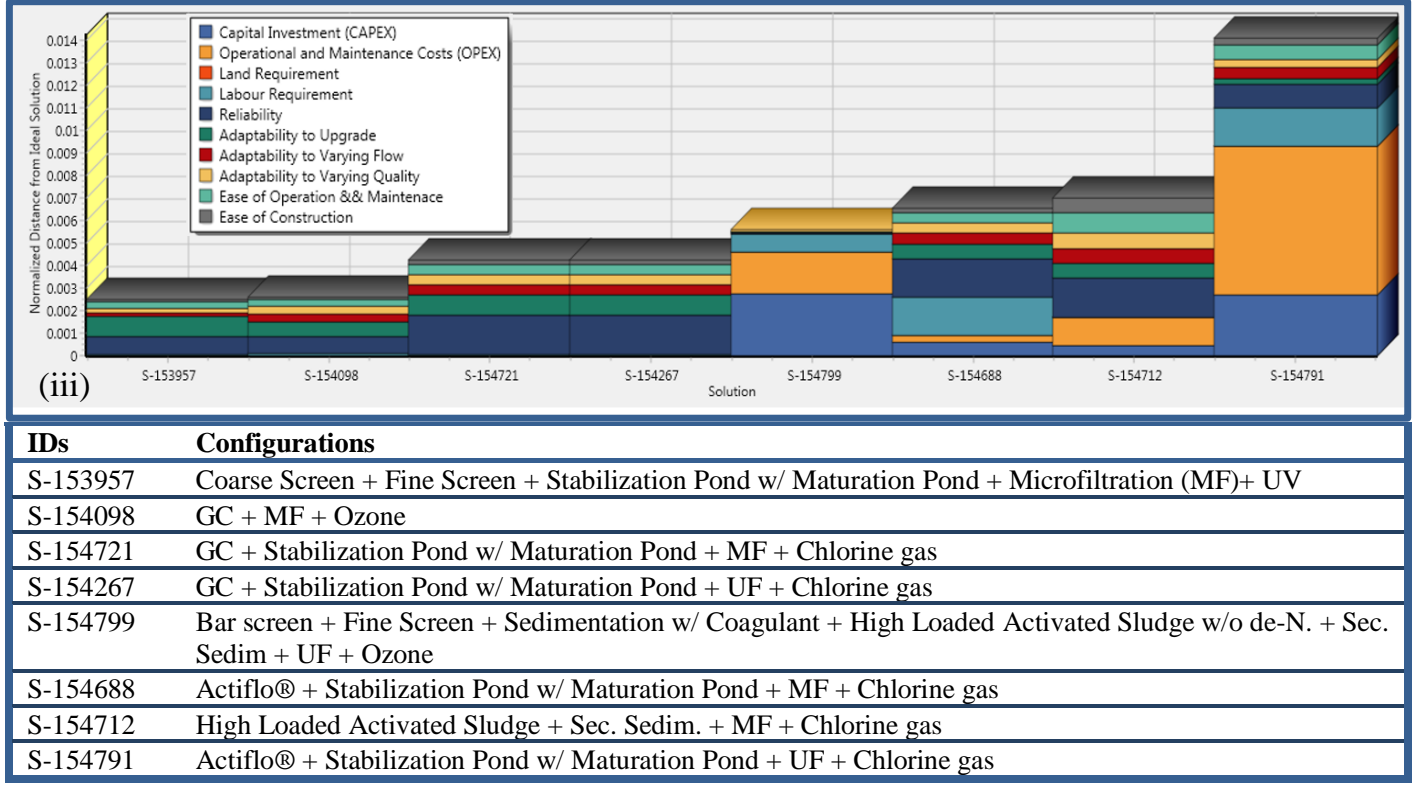

Figure 3: Performance of the optimal WWT trains in this sub-scenario B: (i) contaminant removal star chart; (ii) star chart on the MOO results; and (iii) stacked bar chart on the MCDA results.

Results of the first case study (Sub-scenario A) show that the performances of optimal solutions S309062 (Fine Screen + Dissolved Air Floatation (DAF) w/ Coagulant + High Loaded Activated Sludge w/ de-N + Sec. Sedim. + Soil Aquifer Treatment (SAT) + Ozone) and S-309132 (Grit chamber + DAF $\mathrm{w} /$ Coagulant + Membrane bioreactor (MBR) + SAT + UV) outperform other solutions with respect to both contaminant removal and 4 objectives (see Figure 2(ii)). Both solutions are also ranked high in the MCDA evaluation shown in Figure 2(iii), since both S-309062 and S-309132 display superior performance over the other solutions in the evaluation criteria selected in this scenario. These two treatment trains are closely followed by S-309132, S-309186 in MCDA results (Figure 2(iii)). As mentioned above, Sub-scenario A focuses on an urban area, therefore, land availability is a critical indicator; therefore, many of the solutions are formed of unit processes with small footprints e.g. 
membrane technologies. MBRs require much smaller footprints compared to conventional activated sludge systems or natural treatment processes such as stabilization ponds.

In Sub-scenarios B, on the other hand, skilled labour and reliability of systems are more critical in comparison with land requirement. Therefore, as shown in Figure 3 and Figure 4, there are several natural treatment systems among the optimal solutions in Sub-scenario B, and a number of automated systems (i.e. systems with minimum need of operation and maintenance staff) in Sub-scenario C. This shows the tool is responsive to variation in user preferences. Looking at Sub-scenario B, it is also shown that the solutions are mostly affected by system reliability and CAPEX, as such Solutions S-153957 (Coarse Screen + Fine Screen + Stabilization Pond w/ Maturation Pond + Microfiltration + UV) and S154098 (Grit chamber + Microfiltration + Ozone) outperformed the other solutions based on both MOO and MCDA evaluations.

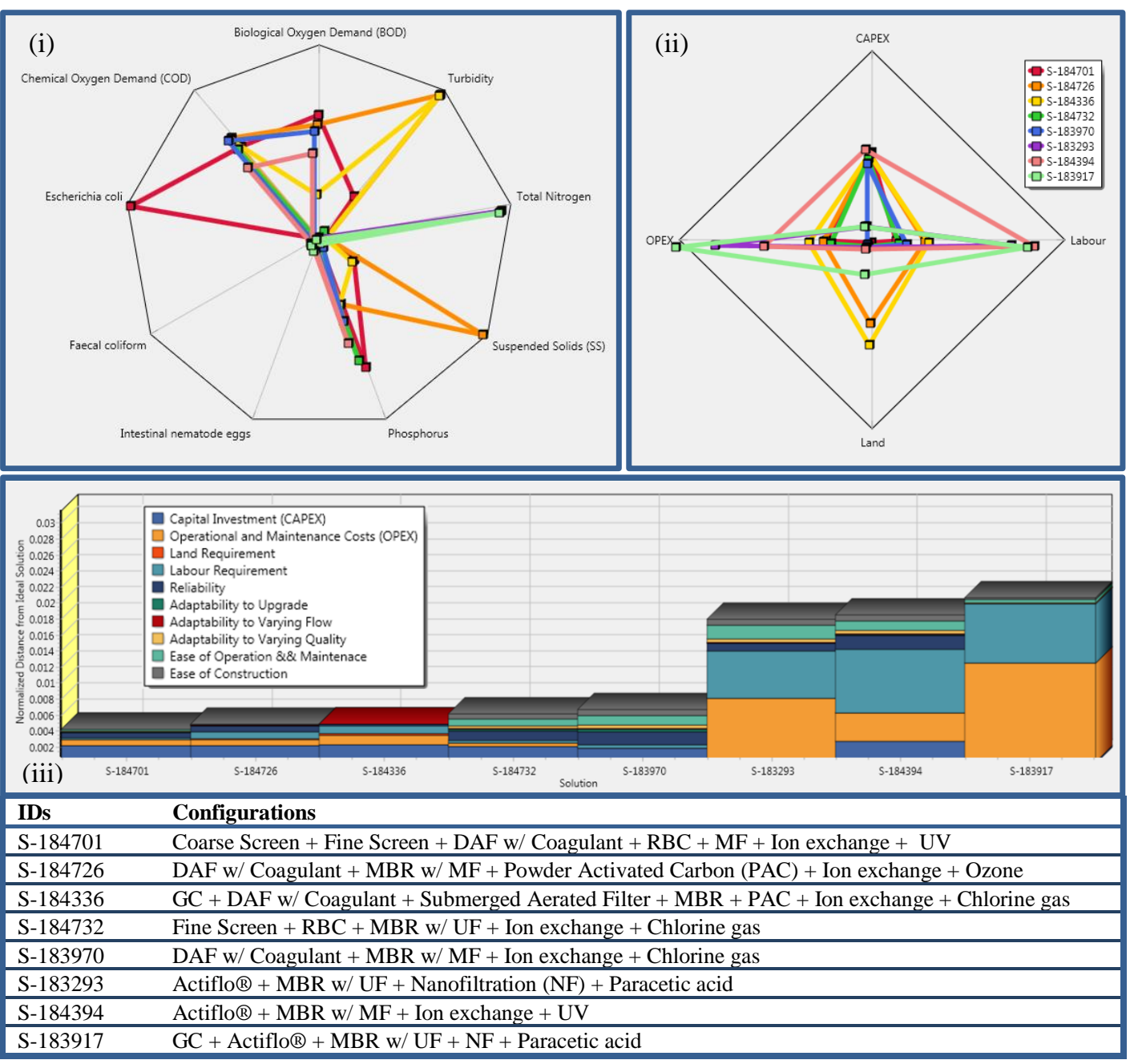

Figure 4: Performance of the optimal WWT trains in this sub-scenario C: (i) contaminant removal star chart; (ii) star chart on the MOO results; and (iii) stacked bar chart on the MCDA results. 
The results in Sub-scenario C show that S-184701 (Coarse Screen + Fine Screen + DAF w/ Coagulant + RBC + Microfiltration + Ion exchange + UV) and S-184732 (Fine Screen + RBC + MBR $\mathrm{w} /$ Ultrafiltration + Ion exchange + Chlorine gas) outperform others with respect to labour requirements. These also display high performance in the other three objectives and in desirable MCDA criteria e.g. ease of construction and ease of O\&M, (see Figure 4(iii)). On the other hand, S-183293 (Actiflo ${ }^{\circ}+$ MBR w/ Ultrafiltration + Nanofiltration + Paracetic acid) shows one of the best performances in CAPEX and removing BOD, COD, Faecal Coliform and phosphorous, however, this solution incurs substantial operational costs, labour requirements and is more difficult to operate; hence, the solution's poor ranking.

The example solutions presented above are intended to demonstrate the functionalities of the developed tool and response to the user inputs. Sanity of the tool provided solutions is yet to be tested further and heavily depends on the input data quality.

\section{Conclusion}

This paper described the development and application of a user friendly decision support tool (WiSDOM) which employs advanced multi-objective optimisation and decision analysis techniques to generate and aid a user select high performance wastewater treatment solutions in a flexible and scalable manner. Technology potential varies with the context within which it is applied. The WiSDOM tool results suggest several optimal solutions for each scenario investigated. A selection of these potential solutions was discussed above with respect to several performance indicators. This selection is very much influenced by selected optimisation objectives, relative weights assigned to different selection criteria, method of optimisation and input data quality. The availability of accurate data on various technological and associated sustainability aspects will enhance WiSDOM utilisation potential. The tool in its current form can facilitate decision making and could form a basis for negotiation between different stakeholders and evaluate the impact of their preferences and constraints on the identification of potential solutions. The tool application can help to shortlist the most promising solutions before the detailed investigation and design of a solution commences.

\section{Acknowledgements}

This paper describes the work carried out under the EC FP7-funded project: Grant agreement no: 308672 "Saraswati". The project sponsors had no involvement in the study design, collection, analysis and interpretation of data or in the writing of the manuscript.

\section{References}

Anagnostopoulos, K., Doukas, H., Psarras, J., 2008. A linguistic multicriteria analysis system combining fuzzy sets theory, ideal and anti-ideal points for location site selection. Expert Syst. Appl. 35, 20412048. https://doi.org/10.1016/j.eswa.2007.08.074

Arroyo, P., Molinos-Senante, M., 2018. Selecting appropriate wastewater treatment technologies using a choosing-by-advantages approach. Sci. Total Environ. 625, 819-827. https://doi.org/10.1016/j.scitotenv.2017.12.331

Aydiner, C., Sen, U., Koseoglu-Imer, D.Y., Can Dogan, E., 2016. Hierarchical prioritization of innovative treatment systems for sustainable dairy wastewater management. J. Clean. Prod. 112, 4605-4617. https://doi.org/10.1016/j.jclepro.2015.08.107 
Chen, J., Beck, M.B., 1997. Towards designing sustainable urban wastewater infrastructures: A screening analysis. Water Sci. Technol. 35, 99-112. https://doi.org/10.1016/S0273-1223(97)00188-1

CWC., 2010. Water and related statistics. Water Planning and Project Wing, Central Water Commission, India.

Deb, K., Pratap, A., Agarwal, S., Meyarivan, T., 2002. A fast and elitist multiobjective genetic algorithm: NSGA-II. IEEE Trans. Evol. Comput. 182-197.

Hakanen, J., Miettinen, K., Sahlstedt, K., 2011. Wastewater treatment: New insight provided by interactive multiobjective optimization. Decis. Support Syst., Multiple Criteria Decision Making and Decision Support Systems 51, 328-337. https://doi.org/10.1016/j.dss.2010.11.026

Joksimović, D., 2006. Decision support system for planning of integrated water reuse projects $(\mathrm{PhD}$ Engineering). University of Exeter, Exeter, UK.

Joksimovic, D., Kubik, J., Hlavinek, P., Savic, D., Walters, G., 2006. Development of an integrated simulation model for treatment and distribution of reclaimed water. Desalination, Integrated Concepts in Water Recycling 188, 9-20. https://doi.org/10.1016/j.desal.2005.04.097

Kalbar, P.P., Karmakar, S., Asolekar, S.R., 2013. The influence of expert opinions on the selection of wastewater treatment alternatives: A group decision-making approach. J. Environ. Manage. 128, 844-851. https://doi.org/10.1016/j.jenvman.2013.06.034

Kalbar, P.P., Karmakar, S., Asolekar, S.R., 2012. Selection of an appropriate wastewater treatment technology: A scenario-based multiple-attribute decision-making approach. J. Environ. Manage. 113, 158-169. https://doi.org/10.1016/j.jenvman.2012.08.025

Karimi, A.R., Mehrdadi, N., Hashemian, S.J., Nabi, B., Tavakkoli, M., 2011. Selection of wastewater treatment process based on the analytical hierarchy process and fuzzy analytical hierarchy process methods. Int. J. Environ. Sci. Technol. 8, 267-280. https://doi.org/10.1007/BF03326215

Kaur, R., Wani, S.P., Singh, A.K., Lal, K., 2012. Wastewater production, treatment and use in India. Presented at the 2nd Regional Workshop on Safe Use of Wastewater in Agriculture, India.

Krovvidy, S., 1998. Intelligent Tools for Wastewater Treatment Design. Comput.-Aided Civ. Infrastruct. Eng. 13, 219-226. https://doi.org/10.1111/0885-9507.00100

Kumar, D., Sharma, S.K., Asolekar, S.R., 2016. Significance of incorporating constructed wetlands to enhance reuse of treated wastewater in India, in: Natural Water Treatment Systems for Safe and Sustainable Water Supply in the Indian Context. IWA Publishing, London, UK, pp. 161-176.

Memon, F.A., Sadr, S.M., Duncan, A.P., Gibson, R., Chatterjee, P., Starkl, M., Prasad, R., Savic, D., Philip, L., Kazmi, A.A., Ghangrekar, M.M., Singh, A., 2016. Development of a stakeholders informed decision support system for optioneering the treatment and reuse of wastewater, in: International Conference On Innovations in Sustainable Water and Wastewater Treatment Systems (ISWATS). Pune, India.

Molinos-Senante, M., Gómez, T., Caballero, R., Hernández-Sancho, F., Sala-Garrido, R., 2015. Assessment of wastewater treatment alternatives for small communities: An analytic network process approach. Sci. Total Environ. 532, 676-687. https://doi.org/10.1016/j.scitotenv.2015.06.059

Muthu Nesa Beula, T., Eswara Prasad, G., 2012. Multiple Criteria Decision Making With Compromise Programming Int. J. Eng. Sci. Technol. IJEST, vol. 4, no. 9, pp. 4083-4086, Sep. 2012. Int. J. Eng. Sci. Technol. 4, 4083-4086.

Plakas, K.V., Georgiadis, A.A., Karabelas, A.J., 2016. Sustainability assessment of tertiary wastewater treatment technologies: a multi-criteria analysis. Water Sci. Technol. 73, 1532-1540. https://doi.org/10.2166/wst.2015.630

Ren, J., Liang, H., 2017. Multi-criteria group decision-making based sustainability measurement of wastewater treatment processes. Environ. Impact Assess. Rev. 65, 91-99. https://doi.org/10.1016/j.eiar.2017.04.008

Sadr, S.M.K., Saroj, D.P., Kouchaki, S., Ilemobade, A.A., Ouki, S.K., 2015. A group decision-making tool for the application of membrane technologies in different water reuse scenarios. J. Environ. Manage. 156, 97-108. https://doi.org/10.1016/j.jenvman.2015.02.047

Zeleny, M., Cochrane, J.L., 1974. Compromise Programming', in Multiple Criteria Decision Making, 1974, pp. 1296-1298., 1st ed. University of South Carolina Press, Columbia, South Carolina. 